\title{
Inferior thyroid artery pseudoaneurysm associated with internal jugular vein puncture: a case report
}

\author{
Jinguang Ruan', Cao Zhang ${ }^{2}$, Zhiyou Peng ${ }^{1}$, David Yue Tang $^{3}$ and Zhiying Feng ${ }^{\text {1* }}$
}

\begin{abstract}
Background: Central venous catheter placement is an important aspect of patient care for the administration of fluids and medications and for monitoring purposes. However, it is still associated with significant morbidity and mortality.

Case presentation: We report a case of iatrogenic inferior thyroid artery pseudoaneurysm during the central line placement due to internal jugular vein puncture. This is a rare complication of central venous cannulation. Fortunately the pseudoaneurysm was monitored closely, diagnosed promptly and obliterated by using radiological intervention. We discuss the risk factors and management of the unintended artery puncture.

Conclusion: The pathway of the management post arterial puncture depends on the size of the needle or catheter, which is direct related to the consequence of arterial injuries. Identifying risk factors is very important to avoid the complications. However, the use of ultrasound guided venipuncture is the most important method to avoid mechanical complications.
\end{abstract}

Keywords: Pseudoaneurysm, Internal jugular vein, Inferior thyroid artery

\section{Background}

The safety and advantages of Seldinger technique for central vein catheter (CVC) placement are well known. However, it is still associated with significant morbidity and mortality. Arterial injury is not uncommon during CVC placement and potentially fatal. Most common arterial puncture is involved in carotid artery [1], but also in vertebral artery [2], thyrocervical trunk [3], innominate artery [4], even internal mammary artery [5] etc. Some literatures showed inadvertent arterial puncture with a small needle occurs in range of 4.2-9.3\% [6-9]. The most devastating complications from arterial misplacement of large-bore catheter $(>7 \mathrm{Fr})$ have an incidence of 0.1 to $1.0 \%$ [1,9-12]. The hematoma in the neck, which can potentially compress the airway [5], hemothorax [13,14], pseudoaneurysm [14], arteriovenous fistula [15], stroke [10,16-19] and death [11,20,21] have been well reported. Here we report a case the patient scheduled for elective partial hepatectomy developed inferior thyroid artery pseudoaneurysm during CVC placement using Seldinger's technique.

\footnotetext{
* Correspondence: fzy1972@zju.edu.cn

${ }^{1}$ Department of Anesthesiology and Pain Medicine, the First Affiliated

Hospital, Zhejiang University School of Medicine, Hangzhou, China

Full list of author information is available at the end of the article
}

\section{Case presentation}

The Case Report was approved by the ethics committee of the First Affiliated Hospital, Zhejiang University School of Medicine and the patient in this study was given written informed consent for her participation. A 51-year old Chinese woman $(158 \mathrm{~cm}, 61 \mathrm{~kg})$ presented with history of primary hepatocellular carcinoma with liver cirrhosis. Elective right-sided hepatectomy was scheduled. She denied any past surgical histories and had no anomalies on the neck in physical examination. All the vital signs were normal. Platelet counts and liver function were within normal range. The International Normalized Ratio (INR) was 1.35 (normal range: 0.851.15). The electrocardiogram and chest $X$-ray showed insignificantly findings prior to surgery.

After radial artery catheterization was placed, general anesthesia was induced with midazolam $2 \mathrm{mg}$, etomidate $16 \mathrm{mg}$, lidocaine $60 \mathrm{mg}$, and fentanyl $0.3 \mathrm{mg}$. Patient was intubated with rocuronium $50 \mathrm{mg}$ on controlled ventilation. A $500 \mathrm{ml}$ saline bag was placed under the right shoulder. Patient was placed in Trendelenburg position and her head was tilted to the left about 40 degree. The right neck was prepared and draped for CVC insertion with high central approach. After the finder needle penetrated obliquely into skin towards the right nipple 
until blood return, an 18-gauge introducer needle with $10 \mathrm{ml}$ spring-wire introduction syringe (Arrow ${ }^{\circ}$ central venous catheter, Arrow International, Asheboro, NC, USA) was inserted to the same site with the similar angle and similar direction as the finder needle did. However, the bright, pulsatile blood was observed during aspiration. The introducer needle was pulled out immediately and local compression was applied for hemostasis. After about 15 min manual compression, a diffused swelling was noted at the base of the right neck. Then CVC via the left internal jugular vein puncture was achieved successfully under the real-time guidance of the ultrasound at one attempt (Arrow ${ }^{\circ}$ central venous catheter, $7 \mathrm{Fr}, 20 \mathrm{~cm}$, 0.32 inches, two lumens; Arrow International, Asheboro, NC, USA). The surgery proceeded smoothly and the patient's swelling in right neck was noted without any pulsation and bruit while transporting to ward.

On postoperative Day (POD) 1, the swelling was still noticeable at the right neck without any signs of pulsation and bruit. Physical compression about $1 \mathrm{~h}$ was applied again. However, the maneuver did not reduce swelling on POD2, and the patient complained of a mild respiratory distress. The emergent Doppler ultrasound and Computed Tomography Angiography were recommended. The ultrasound results (Figure 1) showed that the cervical cystic mass $\left(5^{*} 3.2 \mathrm{~cm}\right)$ was located at the right neck and linked with a near artery; the size of orificium fistula was about $0.2 \mathrm{~cm}$, and the flow velocity reached at $0.68 \mathrm{~m} / \mathrm{s}$. The computed tomography scan of the neck demonstrated a giant hematoma compressing the internal jugular vein and trachea (Figure 2). After consulting with vascular surgeon, right subclavian artery angiography guided by digital subtraction angiography was immediately ordered about 58 hours postoperatively.
A pseudoaneurysm arising from the inferior thyroid artery (Figure 3A) was verified and its orificium fistula was embolized by cook clipHilal/Nester Embolization Microcoil, MWCE- 18-2.0-2- HILAL /MWCE-18- 143-NESTER, Cook Incorporated, Bloomington, USA) (Figure 3B). The procedure was successful by the confirmation of the ultrasound re-scanning without any abnormal flow (Figure 4). The patient remained stable, and was discharged on POD 10 without any sequelae.

\section{Discussion}

After reviewing the various complications of arterial puncture during CVC placement, we found that the majority of the devastating complications in arterial injuries were reported on carotid or vertebral with large-bore catheters [21], rare on small caliber artery like inferior thyroid artery. Only one case report on inferior thyroid artery injury with focal false aneurysm after multiple attempts of CVC placement with 22 gauge finder needle. The patient had platelet abnormality. The false aneurysm of inferior thyroid artery was embolized with coils successfully [22]. Another case reported on unintended inferior thyroid artery cannulation during $\mathrm{CVC}$ placement with 8.5 FG introducer sheath. In this case, 71 year old male patient with liver carcinoma for left-sided hemihepatectomy, vascular surgeon immediately explored the neck and found an enlarged and punctured inferior thyroid artery, which was ligated without further complications [23].

However, in our case, the arterial puncture with 18 gauge introducer needle was made by a 3 rd year resident who was supervised by a senior attending with only one attempt. We postulate that the formation of inferior thyroid artery pseudoaneurysm could be due to following
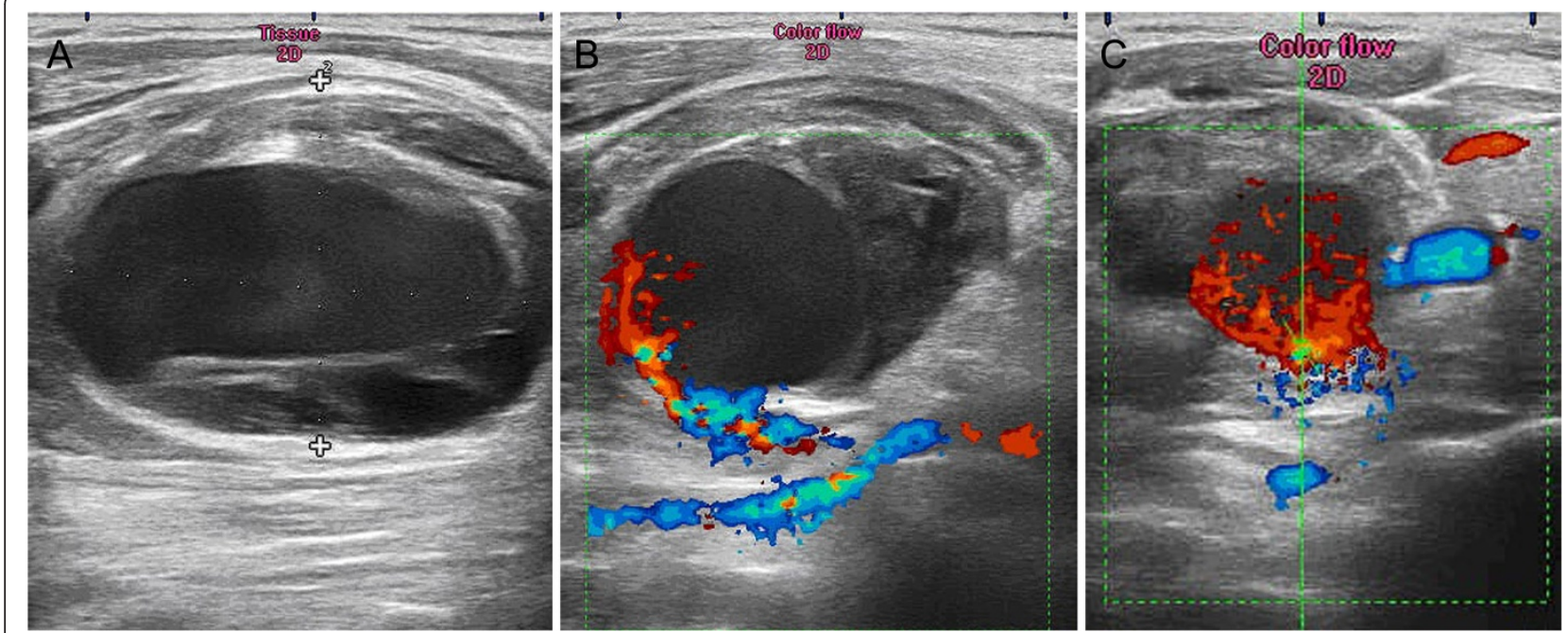

Figure 1 Radiological imaging. A: The cervical cystic mass $(5 * 3.2 \mathrm{~cm})$ was located at the right neck; $\mathbf{B}$ : The cervical cystic mass was linked with a near artery; the size of orificium fistulae was about $0.2 \mathrm{~cm}$, and $\mathbf{C}$ showed the flow velocity reached at $0.68 \mathrm{~m} / \mathrm{s}$. 


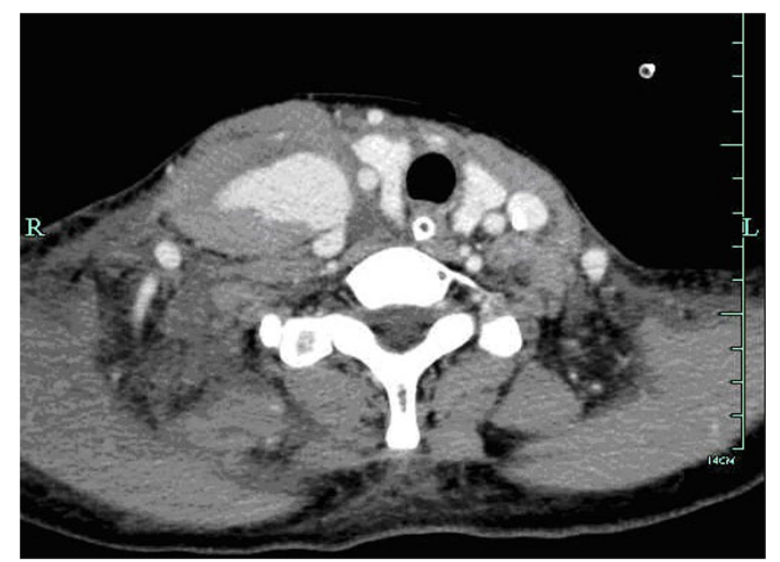

Figure 2 Computed Tomography Carotid Angiography showing the higher density mass $\left(3.6^{*} 5.9 \mathrm{~cm}\right)$ of right neck connected with a branch of the subclavicular artery and compressed the right carotid artery and trachea.

factors. First, the introducer needle was aimed too lateral to carotid artery, even lateral to internal jugular vein, or too low and deep in the neck. Second, the direct compression was applied to the needle entry site on the skin, but maybe not on the punctured site on the artery. Third, an arterial puncture usually results in a periarterial hematoma and is usually self-limiting with application of pressure. However, if the injury to the artery is severe or if coagulation abnormalities exist, a false aneurysm can be produced. Coagulopathy contributed to the formation of hematoma, arteriorial venous fistula, and pseudoaneurysm had been well reported [24-27]. Even blood liver function tests were normal in this patient, the INR was prolonged slightly prior to surgery. And the prothrombin time does not become abnormal until more than $80 \%$ of liver synthetic capacity is lost [28]. INR was not measrued unfornately after surgery during POD1 and POD3. The patient's liver synthetic function might further be compromised by showing abnormal alanine aminotransferase (ALT) and aspartate aminotransferase (AST), bilirubin and albumin on POD1. Those abnormal values resumed

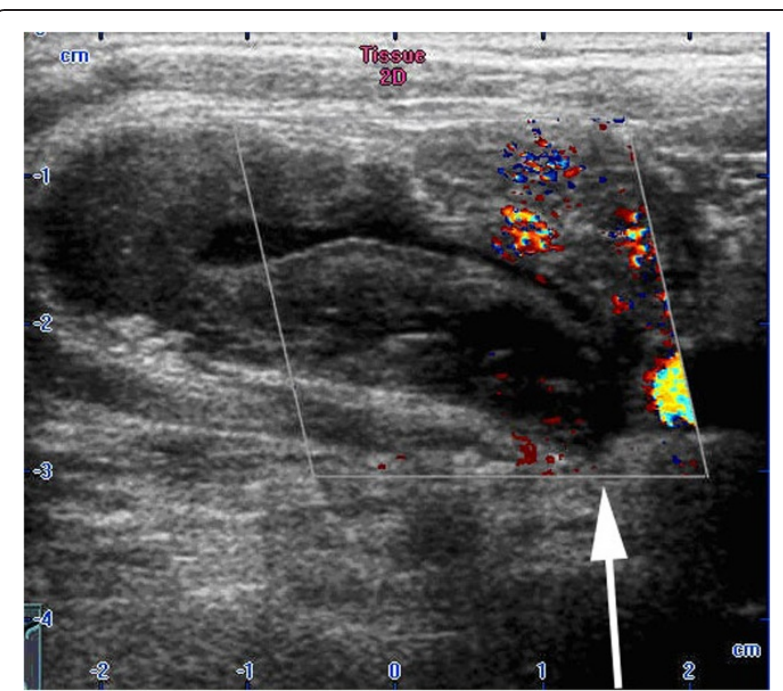

Figure 4 The ultrasound re-scanning showed the right cervical cystic mass without pulsative hemorrhage after embolization.

to normal on postoperative day 3. Therefore, the patient's coagulopathy aggravated during and post surgery. Insufficient clotting factors may theoretically have an increased risk for a delayed closure of an arterial puncture. All those factors above might be the explanations for the formation of pseudoaneurysm of inferior thyroid artery for this case.

Clinical investigation revealed that both small needle and large-bore catheter could result in arterial injuries during CVC cannulation attempts. The management or consequence of arterial punctures is directly related to the size of needle or catheter during CVC placement. The definition of the large-bore catheter is mentioned in some literatures, which indicate unintended arterial cannulation with a 7 French or larger catheter or dilator $[6,21,29]$. There are no definite guidelines about the management of accidental arterial cannulation during central venous catheterization. We concur with MarieChristine Guilbert et al., their recommendation for the management [21]. As soon as operator suspects the large-bore catheter $(>7 \mathrm{~F})$ in artery, leaves the catheter
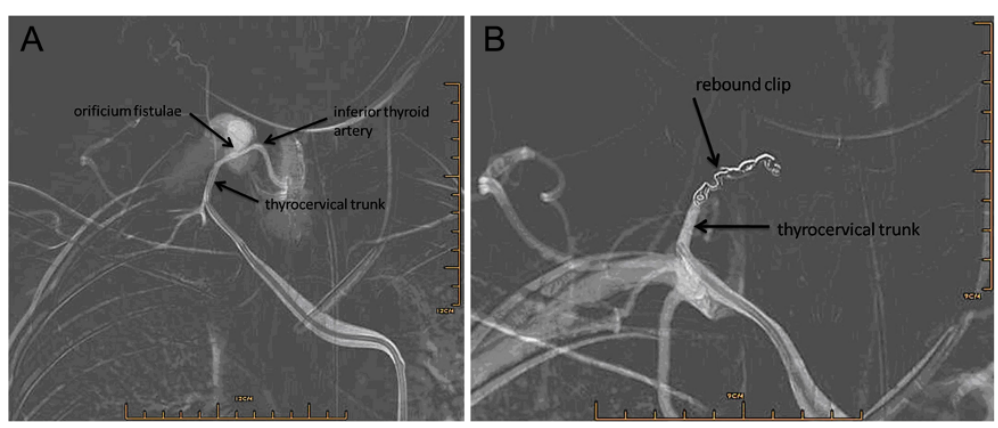

Figure 3 Radiological imaging. A showing a pseudoaneurysm fed from the inferior thyroid artery; B showing the embolization the orificium fistulae of the right inferior thyroid with a cook clip, no more hemorrhage was observed under digital subtraction angiography. 
in place, obtain vascular surgery consultation, and postpones any elective surgery. The definition of small needle is from 20-G to 25-G by reviewing literatures [21]. Accidental arterial punctures caused by those finder needles are usually inconsequential. The pull/pressure technique is acceptable if there are no risk factors [11]. However, small finder needle with multiple attempts on the condition of the arterosclerosis or coagulopathy still can resulted in major complications, such as stroke, pseudoaneurysm, etc. $[10,22,30,31]$. In present case, we fell in the dilemma. No literatures or the consensus define 18 gauge needle as small caliber needle or largebore cannula. No guideline of management of $18-\mathrm{G}$ needle on arterial puncture is found. The pull/pressure technique was taken in our case. The patient developed acute inferior thyroid artery pseudoaneurysm within 3 days. The pull/pressure technique was used because we thought $18 \mathrm{G}$ needle was not much traumatic, but the fact it was traumatic on the patients with high risk factors. The cirrhosis with coagulopathy as risk factor was neglected. No real-time ultrasonography was used during the $\mathrm{CVC}$ attempt; No Doppler ultrasound exam was done immediately post puncture while noticing neck swelling. The investigation should start early postoperatively. Those are the lessons we learn from this case.

By reviewing the literatures, anatomical variations, obesity, history of neck surgery and vessel cannulation, inexperience operator, extreme rotation of the neck, multiple needle attempts, large-bore needle, insertion too deep $(>2 \mathrm{~cm})$ or too laterally, coagulopathy, diseased artery, and low approach of Seldinger's technique, etc., are described as risk factors for potential complications of iatrogenic arterial puncture $[2,21,24,25,30]$. Prevention of arterial injury has been focused on the trainee training and the application of ultrasonography during CVC placement. Meta-analysis of randomized controlled trials [32-42] indicates that, compared with the landmark-guided technique, real-time ultrasound guided venipuncture of the internal jugular vein has a higher first insertion attempt success rate, reduced access time, higher overall successful cannulation rate, and decreased rates of arterial puncture (Category A1 evidence). Though there are still several reports of inadvertent arterial placement of large-bore catheters that have occurred on some unusual locations despite the use of ultrasound guidance with some trainee $[43,44]$.

\section{Conclusions}

In summary, iatrogenic inferior thyroid artery pseudoaneurysm is infrequent complication during CVC placement. To our knowledge, there was only one case of the inferior thyroid artery focal pseudoaneurysm reported [22]. The pathway of the management post arterial puncture depends on the size of the needle or catheter, which is direct related to the consequence of arterial injuries. Identifying risk factors is very important to avoid the complications. However, the use of ultrasound-guided venipuncture is the most important method to avoid mechanical complications [45-48]. This case teaches us that ultrasound guided venipuncture MUST be used routinely. Though ultrasound machine is not well equipped in developing country, it is still highly recommended for real-time ultrasound guidance during the whole period of CVC placement, especially for high risk patients [45-48].

\section{Consent}

Written informed consent was obtained from the patient for publication of this case report and any accompanying images. A copy of the written consent is available for review by the editor of this journal.

\section{Abbreviations}

CVC: Central venous catheter; POD: Postoperative Day; INR: International Normalized Ratio; ALT: Alanine aminotransferase; AST: Aspartate aminotransferase.

\section{Competing interests}

The authors declare that they have no competing interests. No financial arrangements exist which may be interpreted as having the potential to bias the outcome of this case.

\section{Authors' contributions}

ZYF and CZ carried out the anesthesia. JGR, ZYF, ZYP and DYT wrote the manuscript. All authors read and approved the final manuscript.

\section{Acknowledgements}

All contributors for this study are those included in the authors. Meanwhile, no source of funding from any third party was utilized in any phase of study design, writing and publication of the study.

\section{Author details}

${ }^{1}$ Department of Anesthesiology and Pain Medicine, the First Affiliated Hospital, Zhejiang University School of Medicine, Hangzhou, China.

${ }^{2}$ Department of Anesthesiology, the Fourth Affiliated Hospital, Zhejiang University School of Medicine, Yiwu, China. ${ }^{3}$ Department of Anesthesiology, Mercy General Hospital, Sacramento, CA, USA.

Received: 7 October 2014 Accepted: 23 April 2015

Published online: 06 May 2015

\section{References}

1. Golden LR. Incidence and management of large-bore introducer sheath puncture of the carotid artery. J Cardiothorac Vasc Anesth. 1995;9(4):425-8

2. Momiy J, Vasquez J. latrogenic vertebral artery pseudoaneurysm due to central venous catheterization. Proc (Bayl Univ Med Cent). 2011;24(2):96-100.

3. Dwivedi AJ, Cherukupalli C, Dayal R, Krishansastry KV. Endovascular treatment of false aneurysm of the thyrocervical trunk. Vasc Endovasc Surg 2007:41(1):77-9.

4. Wall ML, Davies RSM, Simms MH. Modified trapdoor exposure for open repair of brachiocephalic artery branch injury: case report. Vasc Endovasc Surg. 2008;42(5):500-4.

5. Kindelan J, Crandall B, Whittaker D. Endovascular coiling of an internal mammary artery pseudoaneurysm following placement of an internal jugular central venous catheter. Mil Med. 2010;175(8):619-21.

6. Ezaru CS, Mangione MP, Oravitz TM, Ibinson JW, Bjerke RJ. Eliminating arterial injury during central venous catheterization using manometry. Anesth Analg. 2009;109(1):130-4.

7. Oliver Jr WC, Nuttall GA, Beynen FM, Raimundo HS, Abenstein JP, Arnold JJ. The incidence of artery puncture with central venous cannulation using a 
modified technique for detection and prevention of arterial cannulation. J Cardiothorac Vasc Anesth. 1997;11(7):851-5.

8. Hameeteman M, Bode AS, Peppelenbosch AG, van der Sande FM, Tordoir $J \mathrm{H}$. Ultrasound-guided central venous catheter placement by surgical trainees: a safe procedure? J Vasc Access. 2010;11(4):288-92.

9. Jobes DR, Schwartz AJ, Greenhow DE, Stephenson LW, Ellison N. Safer jugular vein cannulation: recognition of arterial puncture and preferential use of the external jugular route. Anesthesiology. 1983;59(4):353-5.

10. Reuber M, Dunkley LA, Turton EP, Bell MD, Bamford JM. Stroke after internal jugular venous cannulation. Acta Neurol Scand. 2002;105(3):235-9.

11. Shah PM, Babu SC, Goyal A, Mateo RB, Madden RE. Arterial misplacement of large-caliber cannulas during jugular vein catheterization: case for surgical management. J Am Coll Surg. 2004;198(6):939-44.

12. Pikwer A, Acosta S, Kölbel T, Malina M, Sonesson B, Akeson J. Management of inadvertent arterial catheterisation associated with central venous access procedures. Eur J Vasc Endovasc Surg. 2009;38(6):707-14.

13. Eckhardt WF, laconetti J, Kwon JS, Brown E, Troianos CA. Inadvertent carotid artery cannulation during pulmonary artery catheter insertion. J Cardiothorac Vasc Anesth. 1996;10(2):283-90.

14. Nicholson T, Ettles D, Robinson G. Managing inadvertent arterial catheterization during central venous access procedures. Cardiovasc Intervent Radiol. 2004;27(1):21-5.

15. Kulvatunyou N, Heard SO, Bankey PE. A subclavian artery injury, secondary to internal jugular vein cannulation, is a predictable right-sided phenomenon. Anesth Analg. 2002;95(3):564-6.

16. Mainland PA, Tam WH, Law B, Ngan Kee W. Stroke following central venous cannulation. Lancet. 1997;349(9056):921.

17. Sloan MA, Mueller JD, Adelman LS, Caplan LR. Fatal brainstem stroke following internal jugular vein catheterization. Neurology. 1991;41(7):1092-5.

18. Anagnou J. Cerebrovascular accident during percutaneous cannulation of internal jugular vein. Lancet. 1982;2(8294):377-8.

19. Brown CQ. Inadvertent prolonged cannulation of the carotid artery. Anesth Analg. 1982;61(2):150-2.

20. Najafi A, Moharari RS, Khajavi MR, Salimi J, Khashayar P. A giant subclavian pseudoaneurysm following central venous catheterization. J Anesth. 2009;23(4):628-9.

21. Guilbert MC, Elkouri S, Bracco D, Corriveau MM, Beaudoin N, Dubois MJ, et al. Arterial trauma during central venous catheter insertion: Case series, review and proposed algorithm. J Vasc Surg. 2008;48(4):918-25.

22. Debek AH, Jammaleddine GW, Bou-Khalil PK. Inferior thyroid artery injury after attempts of internal jugular venous catheterization. J Cardiothorac Vasc Anesth. 2007:21(3):422-4.

23. Schummer W, Schummer C, Paxian M, Fröber R, Settmacher U. ECG recording of central venous catheter misplaced in inferior thyroid artery. Br J Anaesth. 2005;94(3):296-9.

24. Droll KP, Lossing AG. Carotid-jugular arteriovenous fistula: case report of an iatrogenic complication following internal jugular vein catheterization. J Clin Anesth. 2004;16(2):127-9.

25. Cuhaci B, Khoury P, Chvala R. Transverse cervical artery pseudoaneurysm: a rare complication of internal jugular vein cannulation. Am J Nephrol. 2000:20(6):476-82.

26. Wisheart JD, Hassan MA, Jackson JW. A complication of percutaneous cannulation of the internal jugular vein. Thorax. 1972;27(4):496-9.

27. McEnany MT, Austen WG. Life-threatening hemorrhage from inadvertent cervical arteriotomy. Ann Thorac Surg. 1977;24(3):233-6.

28. Johnston DE. Special considerations in interpreting liver function tests. Am Fam Physician. 1999;59(8):2223-30.

29. Togashi K, Nandate K, Hoaglan C, Sherman B, Bowdle A. A multicenter evaluation of a compact, sterile, single-use pressure transducer for central venous catheter placement. Anesth Analg. 2013;116(5):1018-23.

30. Doerfler ME, Kaufman B, Goldenberg AS. Central venous catheter placement in patients with disorders of hemostasis. Chest. 1996;1 10(1):185-8.

31. Zaidi NA, Khan M, Naqvi HI, Kamal RS. Cerebral infarct following central venous cannulation. Anaesthesia. 1998:53(2):186-91.

32. Bansal R, Agarwal SK, Tiwari SC, Dash SC. A prospective randomized study to compare ultrasound-guided with nonultrasound-guided double lumen internal jugular catheter insertion as a temporary hemodialysis access. Ren Fail. 2005;27(5):561-4.

33. Cajozzo M, Quintini G, Cocchiera G, Greco G, Vaglica R, Pezzano G, et al. Comparison of central venous catheterization with and without ultrasound guide. Transfus Apher Sci. 2004;31(3):199-202.
34. Grebenik CR, Boyce A, Sinclair ME, Evans RD, Mason DG, Martin BNICE. guidelines for central venous catheterization in children. Is the evidence base sufficient? Br J Anaesth. 2004;92(6):827-30.

35. Karakitsos D, Labropoulos N, De Groot E, Patrianakos AP, Kouraklis G, Poularas J, et al. Real-time ultrasound-guided catheterisation of the internal jugular vein: a prospective comparison with the landmark technique in critical care patients. Crit Care. 2006;10(6):R162.

36. Koroglu M, Demir M, Koroglu BK, Sezer MT, Akhan O, Yildiz H, et al. Percutaneous placement of central venous catheters: comparing the anatomical landmark method with the radiologically guided technique for central venous catheterization through the internal jugular vein in emergent hemodialysis patients. Acta Radiol. 2006;47(1):43-7.

37. Mallory DL, McGee WT, Shawker TH, Brenner M, Bailey KR, Evans RG, et al. Ultrasound guidance improves the success rate of internal jugular vein cannulation. A prospective, randomized trial. Chest. 1990:98(1):157-60.

38. Slama M, Novara A, Safavian A, Ossart M, Safar M, Fagon JY. Improvement of internal jugular vein cannulation using an ultrasound-guided technique. Intensive Care Med. 1997;23(8):916-9.

39. Teichgräber UK, Benter T, Gebel M, Manns MP. A sonographically guided technique for central venous access. AJR Am J Roentgenol. 1997;169(3):731-3.

40. Troianos CA, Jobes DR, Ellison N. Ultrasound-guided cannulation of the internal jugular vein. A prospective, randomized study. Anesth Analg. 1991;72(6):823-6.

41. Verghese ST, McGill WA, Patel RI, Sell JE, Midgley FM, Ruttimann UE. Comparison of three techniques for internal jugular vein cannulation in infants. Paediatr Anaesth. 2000;10(5):505-11.

42. Verghese ST, McGill WA, Patel RI, Sell JE, Midgley FM, Ruttimann UE. Ultrasound-guided internal jugular venous cannulation in infants: a prospective comparison with the traditional palpation method. Anesthesiology. 1999;91(1):71-7.

43. Thompson C, Barrows T. Carotid arterial cannulation: removing the risk with ultrasound? Can J Anaesth. 2009;56(6):471-2.

44. Pillai L, Zimmerman P, d' Audiffret A. Inadertent great vessel arterial catheterization during ultrasound-guided central venous line placement: a potentially fatal event. J Vasc Surg. 2011;53(6):74S.

45. Shekelle PG, Pronovost PJ, Wachter RM, McDonald KM, Schoelles K, Dy SM, et al. The top patient safety strategies that can be encouraged for adoption now. Ann Intern Med. 2013;158(5 Pt 2):365-8.

46. Wigmore TJ, Smythe JF, Hacking MB, Raobaikady R, MacCallum NS. Effect of the implementation of NICE guidelines for ultrasound guidance on the complication rates associated with central venous catheter placement in patients presenting for routine surgery in a tertiary referral centre. Br J Anaesth. 2007;99(5):662-5.

47. Lamperti M, Bodenham AR, Pittiruti M, Blaivas M, Augoustides JG, Elbarbary $M$, et al. International evidence-based recommendations on ultrasoundguided vascular access. Intensive Care Med. 2012;38(7):1105-17.

48. Rupp SM, Apfelbaum JL, Blitt C, Caplan RA, Connis RT, Domino KB, et al. Practice guidelines for central venous access. A report by the American Society of Anesthesiologists task Force on central venous access. Anesthesiology. 2012;116(3):539-73.

\section{Submit your next manuscript to BioMed Central and take full advantage of:}

- Convenient online submission

- Thorough peer review

- No space constraints or color figure charges

- Immediate publication on acceptance

- Inclusion in PubMed, CAS, Scopus and Google Scholar

- Research which is freely available for redistribution 